\title{
Endogenous Neurogenesis, Oligodendrogenesis and Angiogenesis after Ischemic Brain Injury
}

Toru Yamashita and Koji Abe*

Department of Neurology, Okayama University Graduate School of Medicine, Okayama, Japan

\begin{abstract}
Since strokes are a major cause of death and result in a drastic reduction in the quality of life, a new strategy to minimize ischemic-related damage is thus required. Recent evidence indicates that endogenous neural stem cells of the subventricular zone give rise to not only neurons but also oligodendrocytes, which can restore a disrupted neuronal network in post-ischemic brain, and various kinds of neurotrophic factors, such as EGF, are known to promote this process. To promote the functional recovery of post-stroke brain, angiogenesis is also essential. It has been suggested that circulating endothelial progenitor cells (EPCs) can play an important role in angiogenesis of the post-stroke brain. The number or function of EPCs can also be modulated by various kinds of factors. For example, VEGF, G-CSF and statins can increase EPC levels. In this review, we discuss the present knowledge of endogenous neurogenesis/oligodendrogenesis/angiogenesis and how to enhance their ability to restore the neuronal network through self-repair strategies.
\end{abstract}

Keywords: Neurogeneis; Oligodendrogenesis; Neural stem cells; Angiogenesis; Endothelial progenitor cells (EPCs)

Abbreviations: NPCs: Neural Progenitor Cells; OPCs: Oligodendrocyte Precursor Cells; EPCs: Endothelial Progenitor Cells; EGF: Epidermal Growth Factor; VEGF: Vascular Endothelial Growth Factor; G-CSF: Granulocyte Colony-Stimulating Factor

\section{Introduction}

Strokes are a major cause of death and result in a drastic reduction in the quality of life. The only effective therapeutic approach is thrombolysis with recombinant tissue plasminogen activator, and a new strategy to minimize ischemic-related damage is thus required. Over the past 10 years, regenerative therapy, which supplies new neurons or oligodendrocytes, has been extensively studied. Two tactics are proposed to supply new neurons or oligodendrocyte into the infarcted brain. One is the transplantation of extrinsic neural stem cells (NSCs) derived from stem cells such as embryonic stem (ES) cells and induced pluripotent stem (iPS) cells [1]. The other is the activation of intrinsic neural stem cells [2,3]. Although stem cell transplantation may be one promising method, tumorigenicity and rejection by immuno-response are potentially large hindrances for the application to a clinical setting. On the other hand, the endogenous capacity for regeneration now draws attention to the development of a novel therapeutic strategy for strokes. In addition, angiogenesis is also required to regenerate the neural network $[4,5]$. In this article, we focus on endogenous neurogenesis/oligodendrogenesis/angiogenesis, and discuss current developments in this field with special emphasis on the therapeutic application for strokes (Table 1).

\section{Intrinsic Neural Stem Cells and Neurogenesis}

Persistent neurogenesis occurs in two restricted regions of the adult mammalian brain including the human brain: the subgranular zone (SGZ) of the hippocampal dentate gyrus [6] and the subventricular zone (SVZ) of the lateral ventricle [7]. In the SGZ, newly born neurons migrate into the granule cell layer and integrate into the neuronal network. In the SVZ, which is a thin cell layer in the lateral walls of lateral ventricles, NSCs continuously produce neural progenitor cells (NPCs) migrating into the olfactory bulb [8]. To discern whether the ischemic condition affects endogenous neurogenesis, we studied the temporal profile of NSC division, migration, and differentiation in the
SGZ and the SVZ in the transient forebrain ischemia gerbil model. We found that the ischemic condition increased the division of NSCs of the SGZ with a peak 10 days after ischemic induction, following which cells migrated into the granule cell layer and differentiated mainly into neuronal cells [9]. Furthermore, we also found that transient forebrain ischemia enhances NSC proliferation in the SVZ with a peak 10 days after ischemia, leading to the migration of more NPCs to the olfactory bulb [10]. These studies indicate that ischemic stimuli could increase the number of NSCs and resulted in enhanced neurogenesis in the two restricted lesions, the SGZ and the SVZ. Many researchers reported that newly born neurons can be found in the post-infarcted lesion including the striatum and cortex in another animal model, the transient focal ischemia model [11,12], which is a mimic model of human cardioembolic stroke. To clarify whether SVZ NSCs supply new neurons to areas injured by ischemia, several study groups have performed region-specific cell labeling and long-term tracing experiments. SVZderived NPCs were also reported to migrate towards the injured striatum after middle cerebral artery occlusion (MCAO). A long-term tracing study revealed that the SVZ-derived NPCs differentiated into mature neurons in the striatum, in which they formed synapses with neighboring striatal cells [13] (Figure 1), implying that the SVZ is one of the harbors supplying newborn neurons to brain lesions damaged by focal ischemia.

\section{Intrinsic Oligodendrogenesis and Future Therapeutic Strategy}

In the adult brain, mature oligodendrocytes have been reported

*Corresponding author: Koji Abe, Department of Neurology, Okayama University Graduate School of Medicine, Okayama, Japan, Tel: +81-86-235-7365; Fax: +8186-235-7368; E-mail: abekabek@cc.okayama-u.ac.jp

Received February 04, 2013; Accepted February 21, 2013; Published February 28,2013

Citation: Yamashita T, Abe K (2012) Endogenous Neurogenesis, Oligodendrogenesis and Angiogenesis after Ischemic Brain Injury. J Neurol Neurophysiol S8: 003. doi:10.4172/2155-9562.S8-003

Copyright: (c) 2012 Yamashita T, et al. This is an open-access article distributed under the terms of the Creative Commons Attribution License, which permits unrestricted use, distribution, and reproduction in any medium, provided the original author and source are credited. 
Citation: Yamashita T, Abe K (2012) Endogenous Neurogenesis, Oligodendrogenesis and Angiogenesis after Ischemic Brain Injury. J Neurol Neurophysiol S8: 003. doi:10.4172/2155-9562.S8-003

Page 2 of 4

\begin{tabular}{|l|l|l|}
\hline Factor/Drug & Suggested effect & \multicolumn{1}{|c|}{ Reference } \\
\hline EGF & Increase both NPCs number and OPCs number \\
\hline Asialo-erythropoietin & Promote the maturation of OPCs & [21] \\
\hline VEGF & Increase EPCs number for angiogenesis \\
\hline G-CSF & Increase EPCs number for angiogenesis & [22] \\
\hline Statin & Increase EPCs number for angiogenesis Promoting re-endothelialization. \\
\hline Cilostazol & Increase EPCs number for angiogenesis & [32,45] \\
\hline
\end{tabular}

Table 1: Scientific evidence showing that the administrated factor/drug can enhance endogenous neurogenesis/oligodendrogenesis/angiogenesis.

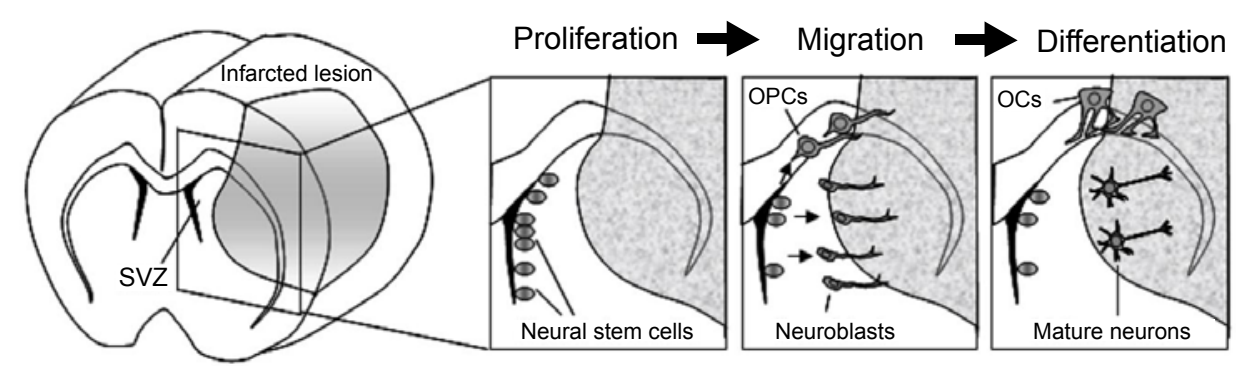

Figure 1: The stage of endogenous neurogenesis/oligogenesis can be divided into three steps: proliferation, migration, and differentiation. Neural stem cells can proliferate in the subventricular zone (SVZ), and a sub-population of these cells can migrate toward the infracted lesion, and differentiate into neurons, or oligodendrocyte (OCs). OPCs: Oligodendrocyte Precursor Cells.

to be produced from local oligodendrocyte precursor cells (OPCs) located in the brain parenchyma. Recent evidence indicates that SVZ neural stem cells also give rise to oligodendrocytes as well as neurons [14]. Menn et al. clearly demonstrated that SVZ astrocytes generate oligodendrocytes, which migrate to the corpus callosum and the white matter tract, by using GFAP-tva transgenic mice and avian retrovirus [15].

In the post-ischemic brain, newly born neurons and oligodendrocytes can be supplied from the SVZ, but this number may be too small for recovery of neurological functions. For example, newly born neurons could replace only $0.2 \%$ of the dead striatal neurons even in the rat MCAO model [11]. It has been reported that various kinds of neurotrophic factors including EGF [16], FGF2 [17], CNTF [18], IGF1 [19] and NGF [20], can promote neurogenesis in animal models. Of note, EGF may be a promising drug candidate because it can increase the number of precursors, promoting not only neurogenesis, but also oligodendrogenesis [21]. A recent study indicated that asialoerythropoietin promoted the maturation of SVZ-derived OPCs and the recovery of neurological function in a hypoxia ischemia mouse model [22]. However, the precise mechanisms that control the proliferation, survival, and/or neuronal maturation of intrinsic NSCs and their progeny must be known so as to use their intrinsic neural cell source for therapeutic purposes.

\section{Endogenous Endothelial Progenitor Cells for Angiogenesis in the Ischemic Brain}

Several studies from human and experimental stroke models indicate that angiogenesis can occur in the adult brain after a stroke $[23,24]$. In the past, the migrated neighboring endothelial cells have been regarded as the main cell resource for the regeneration of injured endothelial cells. However, several research groups reported that bone marrow-derived cells can incorporate and differentiate into endothelial cells at the border of the infarct lesion of the focal cerebral ischemia murine model $[25,26]$. Hess et al. reported that $34 \%$ of vessels of the peri-infarcted area were bone marrow-derived cells [25]. It has also been reported that a number of circulating, very small embryonic-like stem cells mobilized into peripheral blood in patients after a stroke [27]. These results indicate that bone marrow-derived endothelial cells can take part in angiogenesis, and can minimize the effects of an ischemic stroke.

However, increasing scientific reports suggest that there are nonbone marrow-derived cells, which can also give rise to endothelial cells [28]. Recently, tissue-resident stem cells, which were isolated from the heart, have been shown to be capable of differentiating into endothelial cells [29]. Therefore, at present, it seems unclear which organ is the main resource for endothelial progenitor cells (EPCs). However, regardless of the origin, the circulating endothelial progenitors in peripheral blood may play an important role in vascular remodeling after a stroke (Figure 2).

\section{Therapeutic Strategy Promoting Repair of Endogenous Endothelial Progenitor Cells}

As discussed above, much evidence exists to show that EPCs take part in angiogenesis in ischemic tissue. Therefore, many researchers have tried various kinds of agents in the ischemic animal model, and test whether such agents can enhance the mobilization of EPCs, leading to augmented angiogenesis. Firstly, VEGF has been reported to play an important role in angiogenesis through mobilization of EPCs in an animal model and in human subjects [30,31]. Zhang et al. reported that administration of recombinant human VEGF at 48 hours after the induction of ischemia enhanced angiogenesis in the peri-infarcted lesion and significantly improved neurological recovery in the rat model [24]. These results seem to suggest that VEGF can be a promising agent for minimizing ischemic-related injury, although issues regarding its utility as a therapeutic agent remain because administration of VEGF at 1 hour after ischemia increased blood brain barrier leakage, and worsened brain edema [24]. As another candidate, granulocyte colony-stimulating factor (G-CSF) also increased the number of circulating EPCs. To test whether G-CSF can promote angiogenesis, we administrated G-CSF to a focal ischemia rat model, and analyzed angiogenesis. We found that newly born endothelial cells were significantly increased in the G-CSF-treated group, compared 
Citation: Yamashita T, Abe K (2012) Endogenous Neurogenesis, Oligodendrogenesis and Angiogenesis after Ischemic Brain Injury. J Neurol Neurophysiol S8: 003. doi:10.4172/2155-9562.S8-003

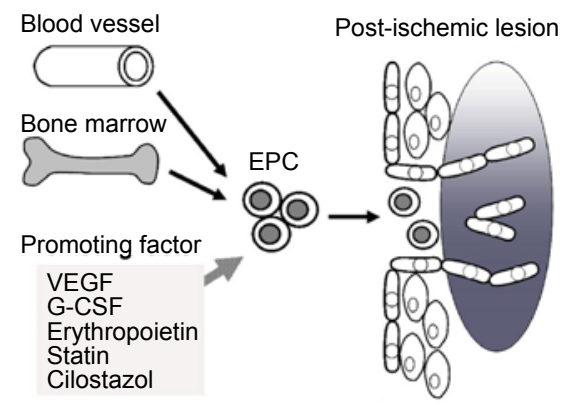

Figure 2: Potential role of endothelial progenitor cells in vascular repair process. Endothelial progenitor cells (EPCs), which derived from bone marrow or blood vessels, have been shown to augment ischemia-induced angiogenesis, either by paracrine effects of cytokines such as VEGF, IGF-1, or direct incorporation into the endothelial layer, following differentiation into mature endothelial cells. Many researchers suggested that some factors such as VEGF, G-CSF, Erythropoietin, Statin, or Cilostazol can promote EPCs mobilization, or enhance the recruitment of EPCs to sites of an injury area.

with the vehicle-treated group [32]. G-CSF has already been applied for idiopathic or chemotherapy-induced neutropenia and related indications such as bone-marrow harvesting, and seems to be a well tolerated drug [33]. Moreover, G-CSF can be administrated to patients subcutaneously. Therefore, G-CSF is now regarded as a promising candidate for modulating ischemic-related injury. In addition, erythropoietin also increased peripheral blood EPCs in mice and in human patients [34]. Interestingly, estrogen, a female sex hormone, has been reported to increase the level of circulating EPCs $[35,36]$. Moreover, exercise also increased the number of EPCs in mice and in men, probably through up-regulation of VEGF and angiopoietin $[37,38]$. The mechanism by which these factors augment EPCs is not fully understood. However, it has been reported that VEGF and exercise-induced mobilization of EPCs was blunted in endothelial nitric oxide synthase (eNOS) knock out mouse, suggesting that eNOS play an essential role in endothelial progenitor cell mobilization [39].

The first evidence for the pharmacological modulation of circulating EPCs by atheroprotective drugs came from studies with HMG-CoA reductase inhibitors (statins). Statins have been shown to increase the mobilization and re-endothelialization of EPCs in the ballooninjured arterial rat model [40]. Chen et al. reported that treatment with atrovastatin for 14 days, which started from 24 hours after a stroke, showed increased VEGF, VEGF receptor 2 and BDNF expression in peri-infarcted lesions, and showed a significant improvement in functional recovery compared with untreated controls [41]. In the myocardial infarction murine model of eNOS null mice, mobilization of statin-induced EPCs was not detected, indicating that eNOS appears to be critical for the mobilization of statin-induced EPCs [42]. In addition, statin treatment of human endothelial progenitors was reported to up-regulate the expression of endothelial integrin $\alpha 5 \beta 1$, which was associated with increased adhesive function of endothelial progenitors toward endothelial cells, indicating that statins may promote EPCs homing to the site of vascular injury [40]. Very recently, cilostazol, which is a selective inhibitor of phosphodiesterase 3, has attracted attention as another candidate for therapy. It has already been reported that cilostazol enhanced angiogenesis probably by promoting EPC mobilization both in the transient forebrain ischemia mouse model [43] and in the carotid balloon injury rat model [44]. In the future, EPCs need to be defined and the mechanisms involved in their beneficial effects need to be studied in detail.
Through new research, multiple novel neuronal self-repair strategies enhancing endogenous neurogenesis/oligodendrogenesis/ angiogenesis should be proposed for clinical settings in the near future.

\section{References}

1. Hung CW, Liou YJ, Lu SW, Tseng LM, Kao CL, et al. (2010) Stem cell-based neuroprotective and neurorestorative strategies. Int J Mol Sci 11: 2039-2055.

2. Leker RR, McKay RD (2004) Using endogenous neural stem cells to enhance recovery from ischemic brain injury. Curr Neurovasc Res 1: 421-427.

3. Nakaguchi K, Masuda H, Kaneko N, Sawamoto K (2011) Strategies for regenerating striatal neurons in the adult brain by using endogenous neural stem cells. Neurol Res Int 2011: 898012.

4. Kaneko Y, Tajiri N, Shinozuka K, Glover LE, Weinbren NL, et al. (2012) Cell therapy for stroke: emphasis on optimizing safety and efficacy profile of endothelial progenitor cells. Curr Pharm Des 18: 3731-3734.

5. Uemura M, Kasahara Y, Nagatsuka K, Taguchi A (2012) Cell-based therapy to promote angiogenesis in the brain following ischemic damage. Curr Vasc Pharmacol 10: 285-288.

6. Gage FH (2000) Mammalian neural stem cells. Science 287: 1433-1438.

7. Alvarez-Buylla A, Garcia-Verdugo JM (2002) Neurogenesis in adult subventricular zone. J Neurosci 22: 629-634

8. Doetsch F, Caillé I, Lim DA, García-Verdugo JM, Alvarez-Buylla A (1999) Subventricular zone astrocytes are neural stem cells in the adult mammalian brain. Cell 97: 703-716.

9. Iwai M, Sato K, Omori N, Nagano I, Manabe Y, et al. (2002) Three steps of neural stem cells development in gerbil dentate gyrus after transient ischemia. J Cereb Blood Flow Metab 22: 411-419.

10. Iwai M, Sato K, Kamada H, Omori N, Nagano I, et al. (2003) Temporal profile of stem cell division, migration, and differentiation from subventricular zone to olfactory bulb after transient forebrain ischemia in gerbils. J Cereb Blood Flow Metab 23: 331-341.

11. Arvidsson A, Collin T, Kirik D, Kokaia Z, Lindvall O (2002) Neuronal replacement from endogenous precursors in the adult brain after stroke. Nat Med 8: 963 970.

12. Teramoto T, Qiu J, Plumier JC, Moskowitz MA (2003) EGF amplifies the replacement of parvalbumin-expressing striatal interneurons after ischemia. $J$ Clin Invest 111: 1125-1132.

13. Yamashita T, Ninomiya M, Hernández Acosta $P$, García-Verdugo JM Sunabori T, et al. (2006) Subventricular zone-derived neuroblasts migrate and differentiate into mature neurons in the post-stroke adult striatum. J Neurosci 26: $6627-6636$.

14. Gensert JM, Goldman JE (1997) Endogenous progenitors remyelinate demyelinated axons in the adult CNS. Neuron 19: 197-203.

15. Menn B, Garcia-Verdugo JM, Yaschine C, Gonzalez-Perez O, Rowitch D, et al (2006) Origin of oligodendrocytes in the subventricular zone of the adult brain. J Neurosci 26: 7907-7918.

16. Ninomiya M, Yamashita T, Araki N, Okano H, Sawamoto K (2006) Enhanced neurogenesis in the ischemic striatum following EGF-induced expansion of transit-amplifying cells in the subventricular zone. Neurosci Lett 403: 63-67.

17. Türeyen K, Vemuganti R, Bowen KK, Sailor KA, Dempsey RJ (2005) EGF and FGF-2 infusion increases post-ischemic neural progenitor cell proliferation in the adult rat brain. Neurosurgery 57: 1254-1263.

18. Emsley JG, Hagg T (2003) Endogenous and exogenous ciliary neurotrophic factor enhances forebrain neurogenesis in adult mice. Exp Neurol 183: 298310 .

19. Yan YP, Sailor KA, Vemuganti R, Dempsey RJ (2006) Insulin-like growth factor- 1 is an endogenous mediator of focal ischemia-induced neural progenitor proliferation. Eur J Neurosci 24: 45-54.

20. Zhu W, Cheng S, Xu G, Ma M, Zhou Z, et al. (2011) Intranasal nerve growth factor enhances striatal neurogenesis in adult rats with focal cerebral ischemia. Drug Deliv 18: 338-343.

21. Gonzalez-Perez O, Romero-Rodriguez R, Soriano-Navarro M, GarciaVerdugo JM.Alvarez-Buylla A (2009). Epidermal growth factor induces the 
Citation: Yamashita T, Abe K (2012) Endogenous Neurogenesis, Oligodendrogenesis and Angiogenesis after Ischemic Brain Injury. J Neurol Neurophysiol S8: 003. doi:10.4172/2155-9562.S8-003

progeny of subventricular zone type B cells to migrate and differentiate into oligodendrocytes. Stem Cells 27: 2032-2043.

22. Kako E, Kaneko N, Aoyama M, Hida H, Takebayashi H, et al. (2012) Subventricular zone-derived oligodendrogenesis in injured neonatal white matter in mice enhanced by a nonerythropoietic erythropoietin derivative. Stem Cells 30: 2234-2247.

23. Krupinski J, Kaluza J, Kumar P, Wang M, Kumar S (1993) Prognostic value of blood vessel density in ischaemic stroke. Lancet 342: 742.

24. Zhang ZG, Zhang L, Jiang Q, Zhang R, Davies K, et al. (2000) VEGF enhances angiogenesis and promotes blood-brain barrier leakage in the ischemic brain J Clin Invest 106: 829-838.

25. Hess DC, Hill WD, Martin-Studdard A, Carroll J, Brailer J, et al. (2002) Bone marrow as a source of endothelial cells and $\mathrm{NeuN}$-expressing cells After stroke. Stroke 33: 1362-1368.

26. Zhang ZG, Zhang L, Jiang Q.Chopp M (2002). Bone marrow-derived endothelia progenitor cells participate in cerebral neovascularization after focal cerebral ischemia in the adult mouse. Circ Res 90: 284-288.

27. Paczkowska E, Kucia M, Koziarska D, Halasa M, Safranow K, et al. (2009) Clinical evidence that very small embryonic-like stem cells are mobilized into peripheral blood in patients after stroke. Stroke 40: 1237-1244.

28. Hillebrands JL, Klatter FA, van Dijk WD, Rozing J (2002) Bone marrow does not contribute substantially to endothelial-cell replacement in transplant arteriosclerosis. Nat Med 8: 194-195.

29. Beltrami AP, Barlucchi L, Torella D, Baker M, Limana F, et al. (2003) Adult cardiac stem cells are multipotent and support myocardial regeneration. Cell 114: 763-776.

30. Asahara T, Takahashi T, Masuda H, Kalka C, Chen D, et al. (1999) VEGF contributes to postnatal neovascularization by mobilizing bone marrow-derived endothelial progenitor cells. EMBO J 18: 3964-3972.

31. Kalka C, Masuda H, Takahashi T, Gordon R, Tepper O, et al. (2000) Vascula endothelial growth factor(165) gene transfer augments circulating endothelia progenitor cells in human subjects. Circ Res 86: 1198-1202.

32. Sehara Y, Hayashi T, Deguchi K, Zhang H, Tsuchiya A, et al. (2007) Potentiation of neurogenesis and angiogenesis by G-CSF after focal cerebral ischemia in rats. Brain Res 1151: 142-149.

33. Schneider A, Kuhn HG, Schäbitz WR (2005) A role for G-CSF (granulocytecolony stimulating factor) in the central nervous system. Cell Cycle 4: 17531757.

34. Heeschen C, Aicher A, Lehmann R, Fichtlscherer S, Vasa M, et al. (2003)
Erythropoietin is a potent physiologic stimulus for endothelial progenitor cell mobilization. Blood 102: 1340-1346.

35. Iwakura A, Luedemann C, Shastry S, Hanley A, Kearney M, et al. (2003) Estrogen-mediated, endothelial nitric oxide synthase-dependent mobilization of bone marrow-derived endothelial progenitor cells contributes to reendothelialization after arterial injury. Circulation 108: 3115-3121.

36. Strehlow K, Werner N, Berweiler J, Link A, Dirnagl U, et al. (2003) Estrogen increases bone marrow-derived endothelial progenitor cell production and diminishes neointima formation. Circulation 107: 3059-3065.

37. Ding YH, Luan XD, Li J, Rafols JA, Guthinkonda M, et al. (2004) Exerciseinduced overexpression of angiogenic factors and reduction of ischemia/ reperfusion injury in stroke. Curr Neurovasc Res 1: 411-420.

38. Laufs U, Werner N, Link A, Endres M, Wassmann S, et al. (2004) Physical training increases endothelial progenitor cells, inhibits neointima formation, and enhances angiogenesis. Circulation 109: 220-226.

39. Aicher A, Heeschen C, Mildner-Rihm C, Urbich C, Ihling C, et al. (2003) Essential role of endothelial nitric oxide synthase for mobilization of stem and progenitor cells. Nat Med 9: 1370-1376.

40. Walter DH, Rittig K, Bahlmann FH, Kirchmair R, Silver M, et al. (2002) Statin therapy accelerates reendothelialization: a novel effect involving mobilization and incorporation of bone marrow-derived endothelial progenitor cells. Circulation 105: 3017-3024

41. Chen J, Zhang C, Jiang H, Li Y, Zhang L, et al. (2005) Atorvastatin induction of VEGF and BDNF promotes brain plasticity after stroke in mice. J Cereb Blood Flow Metab 25: 281-290

42. Landmesser U, Engberding N, Bahlmann FH, Schaefer A, Wiencke A, et al. (2004) Statin-induced improvement of endothelial progenitor cell mobilization, myocardial neovascularization, left ventricular function, and survival afte experimental myocardial infarction requires endothelial nitric oxide synthase. Circulation 110: 1933-1939.

43. Shin HK, Lee HR, Lee DH, Hong KW, Lee JH, et al. (2010) Cilostazol enhances neovascularization in the mouse hippocampus after transient forebrain ischemia. J Neurosci Res 88: 2228-2238.

44. Kawabe-Yako R, li M, Masuo O, Asahara T, Itakura T (2011) Cilostazo activates function of bone marrow-derived endothelial progenitor cell for reendothelialization in a carotid balloon injury model. PLoS One 6: e24646.

45. Toth ZE, Leker RR, Shahar T, Pastorino S, Szalayova I, et al. (2008) The combination of granulocyte colony-stimulating factor and stem cell factor significantly increases the number of bone marrow-derived endothelial cells in brains of mice following cerebral ischemia. Blood 111: 5544-5552.

This article was originally published in a special issue, Stroke:

Cerebrovascular Accident handled by Editor(s). Dr. David Della Morte,

University of Miami, USA 